Modèles linguistiques

ling uistiques

$3 \mid 2010$

Jean-Claude Chevalier. Chroniques de linguistique dans La Quinzaine Littéraire (1975-2010)

\title{
Un inédit d'Ernest Renan
}

Jean-Claude Chevalier

\section{OpenEdition}

Journals

Édition électronique

URL : https://journals.openedition.org/ml/455

DOI : $10.4000 / \mathrm{ml} .455$

ISSN : 2274-0511

Éditeur

Association Modèles linguistiques

Édition imprimée

Date de publication : 1 décembre 2010

Pagination : 211-214

Référence électronique

Jean-Claude Chevalier, « Un inédit d'Ernest Renan », Modèles linguistiques [En ligne], 3 | 2010, mis en ligne le 22 octobre 2013, consulté le 01 juillet 2021. URL : http://journals.openedition.org/ml/455 ;

DOI : https://doi.org/10.4000/ml.455

Ce document a été généré automatiquement le 1 juillet 2021.

(c) Modèles Linguistiques 


\title{
Un inédit d'Ernest Renan
}

\author{
Jean-Claude Chevalier
}

N 1005, 16-31 décembre 2009

Ernest RENAN

Histoire de l'étude de la langue grecque dans l'occident de l'Europe depuis la fin du Ve siècle jusqu'à celle du XIV ${ }^{e}$

Texte introduit et édité par Perrine Simon-Nahum, textes latins et grecs revus et traduits par Jean-Christophe de Nadaï

Cerf, coll. « Patrimoines-Histoire des religions », 790 p.

La publication de ce manuscrit inédit est étonnante
par la taille - cinq gros cahiers! - par la dramaturgie
de la mise en scène (les aventures de l'exercice du grec
depuis l'Antiquité), par la richesse de l'érudition, par
l'ambition du projet; mais surtout par le nom de
l'auteur : Ernest Renan, alors âgé de vingt-cinq ans.
L'ouvrage avait été couronné par l'Institut en 1848,
conservé dans les archives et - surprise! - jamais
publié.

1 Renan avait découvert la passion des langues orientales auprès de M. Le Hir, au séminaire oratorien de Saint-Sulpice; parfois seul élève de ce savant modeste dont l'enseignement tranchait avec la prééminence accordée au latin par l'église tridentine et par les jésuites. C'est à l'étude des langues que Renan, exalté par Herder, avait pensé quand il s'était agi de découvrir les valeurs d'émancipation de la science, mais aussi quand il lui avait fallu gagner sa vie après avoir renoncé à la carrière ecclésiastique ; alors, il se tourna vers l'agrégation aussi bien que vers le doctorat ; mais fut rapidement rebuté par l'ennui et la médiocrité des cours universitaires. Les sciences le tentèrent un moment, mais davantage la science des langues orientales qui correspondait vraiment à la pente d'esprit de l'ancien élève de M. Le Hir. Comme l'écrit l'éditeur : 
À une approche comparatiste qui doit autant à la linguistique qu'à la grammaire comparée, autant à Bopp qu'à Burnouf (...) s'ajoute un arrière-plan théologique indispensable pour décrypter le tableau que Renan dresse du Moyen Âge et des forces qui s'y déploient. L'étude de Renan, tout en puisant son inspiration dans la tradition des grandes histoires littéraires nationales, se sépare de cette volonté encyclopédique en mettant résolument en avant un parti pris (p. 32).

Ce parti pris, c'est la recherche d'un « centre qui, écrit le jeune Renan à l'abbé Cognat, en 1845, est philosophie, théologie, science, littérature, etc., qui est Dieu, suivant moi (p. 33) ». L'histoire de la diffusion du grec, fondée sur une érudition " hors du commun », apporte une réponse à la question posée au monde par l'ancien séminariste: "Comment assurer la spiritualité de l'âme (p. 10) ?».

Ajoutons un contact manuel avec la réalité des œuvres. Il poursuit les manuscrits ; ainsi dans les bibliothèques de la région d'Avranches, où il a découvert un ouvrage inédit du philosophe Jean Scot Érigène et aussi un dictionnaire gréco-latin du $\mathrm{X}^{\mathrm{e}}$ siècle inconnu jusqu'ici. Il obtient des notes de ses amis Ozanam et Egger, prises au monastère du Mont-Cassin. Il y ira lui-même en 1850. Pour assurer ses arrières, il suit, dans la jeune École des chartes, des cours de paléographie.

Et décrit sur plus de 700 pages les convulsions et métamorphoses des mouvements des langues, sur fond de catastrophes et de crises de civilisation, depuis la fin de l'Empire romain jusqu'à la prise de Constantinople (1453) et l'explosion de la Renaissance. Évocation classique aujourd'hui, plus surprenante à l'époque.

Dans la Rome de l'Empire, le grec est constamment présent. « Le christianisme primitif est tout grec ", écrit Renan. À partir du IV siècle, le latin revient en force et le grec se replie sur Byzance. Quant à l'hébreu, il sort peu du peuple juif.

6 Mais le grec ressurgit en Irlande, puis en Grande-Bretagne avec le latin. Et de là s'introduit chez les Carolingiens, prend la Normandie comme carrefour au $\mathrm{X}^{\mathrm{e}}$ siècle. Plus loin, l'Espagne fait cohabiter trois cultures : latine, grecque et arabe. Ici triomphe le Renan philologue orientaliste : le manuscrit est parcouru d'exemples empruntés à la langue arabe, illustrant le rôle de passeurs que Juifs et Musulmans jouèrent dans la circulation des textes. Ce que commente justement l'éditeur :

Sa connaissance des langues orientales donne à son travail un souffle qui en fait, au-

delà d'une simple étude d'érudition, une œuvre de réflexion historique (p. 51).

On ne peut que résumer à grands traits un travail d'une érudition incroyable pour l'époque, qui multiplie les croisements, les métamorphoses, le rôle que jouent les cultures dans ce qu'on appellerait aujourd'hui les mutations de l'épistémè. Au XI siècle, l'ouverture italienne favorise les échanges avec le grec de Constantinople et l'influence s'en marque jusqu'en peinture (tel Cimabue, note Renan). On trouve partout disséminés des mots grecs. Courants manifestés dans les compilations de glossaires qui seront utilisées jusqu'à la Renaissance comme supports de culture : Papias, Uguccio de Pise ; ou bien Jean Balbi de Gênes et le Glossarium d'Alexandre de Villedieu. Renan a tout vu ou, du moins, tout parcouru de ce savoir en miettes : des "répertoires de bribes », ditil. Le latino-grec, jusqu'au XII ${ }^{e}$ siècle, est limité à la Calabre et à l'Italie; ailleurs, presque toujours fragmentaire ou borné à certains couvents. Où parfois on recopie en caractères latins, sans guère comprendre.

8 La culture gréco-arabe est localisée chez les Maures d'Espagne et chez les Juifs. Qui très souvent ignoraient le grec; ils utilisaient des versions orientales et les reproduisaient : 600000 volumes à Cordoue! C'est à Cordoue que Maïmonide donne au judaïsme une 
forme philosophique, popularise Aristote, mais aussi Averroès. L'influence des translations juives s'étendra jusqu'en Russie, par l'intermédiaire de Cyrille et Méthode. Les Juifs seront des passeurs d'un côté avec les Arabes (la science arabe) et avec les Grecs, de l'autre avec l'Occident latin, en textes philosophiques, bien sûr, mais aussi dans les fabliaux et les contes. "Laborieux rabbins!", s'écrie Renan qui mesure l'importance de la diffusion et s'enivre de se faufiler dans ces réseaux d'échanges instaurés par des savants plurilingues comme lui : Nicolas de Lyre, Paul de Burgos ou Raymond Martini.

Le XII ${ }^{\mathrm{e}}$ siècle a instauré en Occident la révolution scolastique, dominée par Aristote, le nouveau : la philosophie supplante les études littéraires et justifie la prééminence de la dialectique, articulée en trivium et quadrivium. Période d'intenses agitations accélérées par les croisades; Renan note que la quatrième croisade ramènera en Occident des fragments inconnus d'Aristote. Les transferts de langue font partie du mouvement: Pierre le Vénérable, abbé de Cluny, traduit le Coran; dominicains et franciscains s'exercent au grec et à l'arabe. Renan multiplie avec ivresse les noms des chercheurs et note que c'est au XIII ${ }^{\mathrm{e}}$ siècle qu'arrivent des textes complets. Aristote devient LE Philosophe, tous ses textes sont répandus. De Platon, on connait surtout le Timée et le Phédon, des commentaires et on utilise en variations Épictète, Porphyre, Proclus, Galien et Hippocrate; et des textes d'alchimistes. On pille Boèce et Isidore. Arrivent aussi des versions, plus ou moins fidèles, des poèmes homériques. Et, pour interpréter, Evrard écrit le Græcismus.

10 L'Allemagne se met de la partie, comme derechef l'Angleterre. Une foule d'érudits traduisent du grec et de l'arabe, mais aussi Raymond Lulle et Pierre d'Espagne.

11 C'est enfin la Renaissance qui redécouvre en Italie le bonheur des études grecques, le culte du beau et du bien. Hellénistes, les gens de lettres comme Pétrarque et Boccace avec leurs amis, qui se pressent aux cours de Chrysoloras ou de Georges de Trébizonde. Et l'Aretin. Renan s'abandonne avec délices à de longues énumérations de noms, symboles d'une nouvelle culture, de nouvelles études de langue, celles de Gaza et de Lascaris.

12 Livre envoûtant d'un jeune humaniste exalté, ivre de cinq siècles d'échanges épistémiques zébrant le monde occidental. 